\title{
Efectos de la disonancia pragmática de los adultos en la audiencia infantil de la CAM: 2006-20081
}

\author{
Franciani Bernardes, Investigadora del Instituto de Estudios de la Democracia. Universidad CEU San Pablo \\ Teresa Torrecillas Lacave, Investigadora del Instituto de Estudios de la Democracia. Universidad CEU San Pablo
}

Resumen:

Los resultados de las investigaciones de Núñez Ladevéze y Pérez Ornia comprobaron una notable quiebra entre los criterios y la conducta de la familia en relación a los mandatos televisivos. Esta conducta incoherente detectada en los padres ha dado origen al concepto de disonancia pragmática (Núñez Ladevéza y Pérez Ornia, 2002). En el estudio que aquí se realiza queremos saber si los niños notan la diferencia entre lo que se dice y lo que se hace. ¿Se dan cuenta los hijos del comportamiento disonantes de sus padres? Estudiaremos la mediación en las familias de la Comunidad de Madrid y consecuentemente la percepción de los hijos con relación a la actuación de sus padres en todo que lo que engloba la relación que establecen con el medio.

Palabras clave:

Disonancia pragmática, televisión, niños.

Abstract:

The results of investigations into Núñez Ladevéze and Pérez Ornia found a notable failure among the criteria and conduct of the family in relation to the television mandates. The bankruptcy has led to the dissonance pragmatic concept. The study here is that we want to know whether the children noticed the difference between what is said and what is done. Children perceive the behaviour of their parents dissonant? We look at mediation in the families of the Community of Madrid and consequently the perception of children in relation to the actions of their parents in what it encompasses all that the relationship established with the medium.

Keywords:

Pragmatic dissonant, television, children.

\footnotetext{
1 Esta investigación se enmarca en el proyecto de investigación Producción de los contextos de recepción de la audiencia infantil en España: El lugar de la familia. Estudio financiado por el Ministerio de Educación y tiene como investigadores principales los profesores Luis Núñez Ladevéze de la Universidad CEU San Pablo, José Ramón Pérez Ornia de la Universidad Complutense de Madrid y Javier Callejo de la Universidad de Educación a Distancia.
} 


\section{Introducción}

Frente a la creciente preocupación de padres, tutores, educadores, instituciones y autoridades sobre la influencia que ejerce la televisión en el desarrollo cognitivo y emocional de los niños, el campo de investigación sobre la televisión y la infancia ha crecido considerablemente. Aunque los niños sean la parcela de la población que menos ve televisión (Núñez Ladevéze y Pérez Ornia, 2002:113-143), son centro de atención porque se trata de un sector de la población que está en fase de formación, de aprendizaje y de desarrollo social. Se han publicado datos alarmantes que constatan realidades como que el 75\% del tiempo que los niños pasan frente al televisor lo dedican a visionar programación no infantil. A los niños les gusta la programación de adultos y el momento de mayor audiencia infantil en el medio televisivo se registra a partir de las $22.00^{2}$. Aunque hemos constatado que los padres se preocupan por la influencia que la televisión pueda ejercer sobre sus hijos, hemos observado, en el estudio que aquí se presenta, que las familias poco hacen para que los niños estén educados para ver televisión.

Con el objetivo de observar y analizar los procesos de mediación familiar, estudiaremos la opinión de los hijos en relación a la actuación de sus padres en todo que lo que tiene que ver con la relación que establecen con el medio. Partiendo de la suposición de que los niños perciben la discordancia entre conducta y acción y que tal comportamiento de los padres queda reforzado por una continua y repetitiva actitud contradictoria, tal paradoja puede resultar poco pedagógica al universo infantil. Es decir, si por ejemplo, los padres imponen determinadas reglas para que el niño no vea un programa y en otro momento dejan que lo vea, sin darle explicaciones, queda fortalecida la incoherencia educativa que también puede ser propensa a extenderse a otros espacios del campo cognitivo del niño.

\section{Objetivos y metodología}

En nuestro estudio tenemos como objetivo principal observar como perciben los hijos el comportamiento disonante de los padres en relación a las normas televisivas. Para eso nos proponemos analizar el discurso de los padres sobre las normas y criterios que sostienen con respecto a la televisión; el tipo de mediación familiar que ejercen en sus hogares con relación al uso y consumo que hacen los hijos de la TV así como la percepción de los niños de tal intervención.

\footnotetext{
2 Véase: “Los niños prefieren los videojuegos, el móvil e Internet a la televisión”, artículo publicado en el periódico El País del lunes 23 de mayo de 2005, citando un estudio realizado en la Facultad de Comunicación de la Universidad de Navarra.
} 
Para alcanzar los objetivos que nos hemos propuesto, aplicamos dos técnicas metodológicas cualitativas: el grupo de discusión, a los hijos y la entrevista en profundidad, a los padres. En ambas situaciones ha sido posible estudiar los sujetos frente a sus gustos, necesidades, vivencias y percepciones más concretas.

Para el grupo de discusión hemos trabajado con niños de 7 a 12 años de la Comunidad de Madrid. Las clases sociales representadas han sido la clase media y la baja. Hemos realizado cuatro grupos de discusión con siete participantes en cada uno, considerando que dos grupos fueron realizados con niños de colegios privados y los otros dos con niños de colegios públicos. Para definir la segmentación social, nos hemos basado en la profesión de los padres, la localización de la vivienda, y en el colegio que estudian los niños. Para que fuese posible la analogía de los discursos entre padres e hijos se hicieron 12 entrevista en profundidad realizadas a padres de las mismas segmentaciones sociales que tuviesen hijos de la misma franja de edad de la muestra aplicada a los grupos de discusión.

Para la realización de las técnicas metodológica nos hemos apoyado en un guión elaborado anteriormente con la colaboración del profesor y sociólogo, Javier Callejo3 ${ }^{3}$

\section{Resultados}

La preocupación de los padres sobre el consumo televisivo de los hijos ha sido más notable en la clase media, así como la disonancia pragmática. Aunque los tutores hayan asegurado que sus hijos ven pocas horas de televisión o que solamente ven programación adecuada a sus edades, la respuesta de los niños no coincide con tal afirmación. Los padres de esta clase social se han mostrado empeñados en aplicarles reglas a los hijos, sin embargo, se contradicen en la forma de actuar: les aplican determinadas normas de conducta con respecto a la pequeña pantalla, pero en general no actúan. Por otro lado, el autoritarismo excede el criterio educativo de que hay que enseñar a los hijos a ver la tele. Es frecuente el "apagar la tele", o prohibirles de ver un programa sin explicaciones.

- yo soy muy mandona. Aquí como es mi casa se ve lo que digo yo. (...) No les digo 'pues no la pongáis', pero si yo me enterara por ejemplo que ve con mi madre Pasión de Gavilanes se lo prohibiría sin ninguna explicación. No sé si es bueno o es malo pero yo no la dejaría ver" (Madre, clase media, Madrid)

- $\quad$ Pues ven 'Los Simpson' en contra de mi voluntad porque al final se ríen mucho y pasan un buen rato. $Y$ el resto porque son series divertidas que normalmente suelen tener moraleja. Por ejemplo, no se ve 'Gran

\footnotetext{
Javier Callejo es profesor de la Universidad Nacional de Educación a Distancia (UNED). Es experto en grupos de discusión y autor de una serie de libros publicados en el tema en cuestión.
} 
Hermano' porque ya lo he prohibido expresamente”. (Madre, clase media, Madrid)

- $\quad$ "Sí, sí, les prohíbo ver algún tipo de programa. Sí, como Gran Hermano. Hay veces que no doy razones, no es el programa adecuado, no tienen la edad adecuada. Y no ven cosas que son un poco soeces, un poco desagradables; entonces digo que no y punto y otras veces si, que no es un programa educativo y que no, no lo deben ver". (Madre, clase media, Madrid).

Hay incoherencia en los mandatos de los padres sobre el uso televisivos y los niños lo perciben claramente, la consecuencia es la confusión que manifiestan para entender lo que pueden o no ver, así como sobre la calidad de sus contenidos.

- $\quad$ "A veces por el nombre no lo quieren ver, pero si estas viendo, ves que no es tan malo como dicen tus padres. Me hablaban de una telenovela, 'Bea', que no servía para nada y empezaron a ver y ahora están enganchados". (Niña 11 años, clase media, Madrid)

- $\quad$ "Es que siempre que estoy viendo algo que no me dejan ver, estoy con el mando así (lo enseña preparado, levantado.) para que pueda cambiar si pasan”. (Niño 11 años, clase media, Madrid)

- $\quad$ "Mi hermana que tiene trece años tampoco le dejan ver (Shin-Chan), pero cuando ya iba a empezar y digo ‘¿Que haces viendo eso?’ y no le digo nada, y voy a la cocina y digo 'mamá, que Sara está viendo Shin-Chan!' y mi madre dice 'ah, déjala, que no pasa nada’”. (Niño, 11 años, clase media, Madrid)

En la clase baja la situación cambia de posición. Se ha observado en esta segmentación social una libertad más explícita en lo que se refiere a los mandatos televisivos. Los padres suelen confiar en la programación que ven los hijos, a pesar de que hayan afirmado que se preocupan por los contenidos violentos y erótico/sexuales. También podemos afirmar que cuando están en casa no es habitual que controlen el visionado de los niños, además se fían de la programación. Aunque haya reglas que cumplir, como ver la televisión después de hacer los deberes (una respuesta frecuente), no se han mostrado empeñados en hacer que sus hijos las cumplan.

- “Cuando yo llego del trabajo y está viendo la novela, le digo que cambie la novela. Y le digo: 'Erica, cosas muy fuertes no quiero que veas'. Además como tiene muchos deberes se va a su habitación a hacerlos”. (Madre, clase baja, Madrid)

- $\quad$ "Pues como no tengo telepatía... Pero ella ve más o menos lo mismo. Trabajo todo el fin de semana, excepto los martes que libro. Puede ver más de 4 horas de televisión un sábado por la mañana, pero es una buena opción para que mi madre esté más desahogada". (Madre, clase baja, Madrid) 
- La niña se levanta a las 11 y está hasta el mediodía viendo la tele. Por ejemplo, el sábado salgo a las tres, tres y media, y cuando llego la niña ya está viendo la televisión.” (Madre, Clase baja, Madrid)

Los niños de esta segmentación han afirmado no encontrar ningún problema para ver lo que quieren en la tele. La falta de criterio de las familias de clase baja también se extiende a otros ámbitos, como por ejemplo, a la hora de acostar a los niños. Al contrario de los hijos de clase media, que suele tener un horario regular para dormir, los niños de clase baja han demostrado que se acuestan más tarde y de forma irregular. Por esa razón, hemos concluido que son los que más consumen programación de prime time. Un hecho curioso que hemos observado en el discurso de los niños de esta segmentación social ha sido la explicación de sus padres para que no vean la televisión mucho tiempo: el gasto de luz. En el general son más libres para elegir la programación. Aunque los padres les pongan reglas, el no cumplimiento no es un problema concreto.

- $\quad$ "A mí no me dicen nada. Yo veo el tiempo que yo quiera. Excepto cuando me dicen que la apague porque se gasta mucha luz. No me importa y me pongo a jugar". (Niña 10 años, clase baja, Madrid).

-

"Me fue a un bautizo y hasta que llego en casa y me acueste ya eran las 3.30 (de la madrugada) y he puesto la tele. Es que a las 4.30 echan 'El cuerpo del deseo'”. (Niña 12 años, clase baja, Madrid).

- $\quad$ "Que cuando yo era pequeña sin darme cuenta vi a un programa un poquito de mayores y mi madre 'No hija, no puedes ver eso porque es un programa de mayor'” (Niña 10 años, clase baja, Madrid).

Las familias, en general suelen estar más pendientes de los niños menores de 8 años, principalmente si tienen hijos mayores. A los diez años los hermanos mayores adquieren una cierta independencia en el consumo de televisión. Uno de los factores que hemos observado para explicar tal actitud es que la influencia de la programación en los menores suele ser más explícita. En los propios grupos de discusión, los niños menores nos ejemplificaban de forma clara y aparente lo que aprendían de los personajes de sus programas preferidos. Por ejemplo, al hablar de un programa de lucha, un niño de 8 años se tira al suelo y simula una lucha con sus adversarios imaginarios; otro niño se mete la mano por debajo de las axilas para producir un ruido corporal que ha aprendido con Shin-Chan, protagonista de una serie japonesa que lleva su nombre. Siguiendo las influencias de la misma serie, otra niña reproduce la voz del personaje japonés para enseñarnos su frase preferida: “iculete! ¡culete!”.

En los niños más jóvenes la influencia de la televisión se presenta de forma aparente, pero eso no significa que los niños mayores estén exentos a los posibles efectos de los contenidos televisivos. Aceptando metodológicamente los supuestos teóricos de Piaget (1975), el aprendizaje es un constante ir y venir desde los 
procesos de asimilación hasta el ajuste de los juicios en las estructuras que posee el individuo. En este sentido debemos considerar que el niño tendrá interés en programas cuyo lenguaje verbal y audiovisual corresponda a la etapa de desarrollo que le corresponda, y que serán sus necesidades las que le motivarán ante determinada programación, por esa misma cuestión son los adultos los que tienen la función de enseñarles a ver la tele (Orozco Gómez, 1991).

\section{Conclusiones}

La falta de coherencia por parte de los padres en lo que se refiere a las normas televisivas dificulta el proceso de aprendizaje infantil de ver televisión. Si los padres y tutores no establecen las normas y criterios de manera adecuada, es la propia televisión la que los establecerá (García de Cortázar et. al., 1998:27). La compañía de un miembro de la familia mientras el niño ve la tele constituye una de las características a la que se llama mediación. La presencia de un adulto puede implicar la posibilidad de una apropiación más comentada de la programación y eventualmente la posibilidad de tomar un mayor distanciamiento de lo que es transmitido en la pantalla. Cuando se ve la tele solo, no se tiene acceso inmediato a la censura de otra persona a lo que se está viendo. En el caso de los niños pequeños eso puede ser determinante para su interacción con la televisión. Los límites físicos del espacio donde se ve la televisión también constituyen otro tipo de mediación situacional (Orozco Gómez, 1996), una vez que se tornan posibles ciertos tipos de interacción. Si los padres no acompañan a los hijos durante el visionado, les están posibilitando una apertura al contenido en su esencia, sin ofrecerles los filtros necesarios para una adaptación y mejor inserción del contenido con sus interpretaciones y valoraciones.

\section{Referencias bibliográficas}

García de Cortázar, M., Callejo Gallego, J. y otros (1998): El tercero ausente. Investigación empírica sobre el papel de los adultos en la relación entre niños y televisión. Madrid: UNED.

Núñez Ladevéze, L. y Pérez Ornia, J. R (2002a): “El conflicto pragmático de los responsables de la audiencia infantil”, en Reis, no 99, p. 113-145.

- (2002b): "Los gustos de la audiencia infantil y la producción televisiva. El conflicto pragmático de los responsables de la audiencia infantil”, en Reis, nº. 94, pp. 113-143.

Orozco Gómez, G. (1996): Televisión y Audiencias: un enfoque cualitativo. Madrid: Ediciones De La Torre. 
Orozco Gómez, Guillermo (1991): "La audiencia frente a la pantalla: una exploración del proceso de recepción televisiva”. Diálogos de la Comunicación, junio, $\mathrm{n}^{\circ} .30$.

Piaget, J. (1975): A equilibração das estruturas cognitivas. Rio de Janeiro: Zahar.

El País (2005): “Los niños prefieren los videojuegos, el móvil e Internet a la televisión”, 23 de mayo. 